«Кунаковский-2», «Тоннельный-6», «Невинномысский-1» на территории Андроповского и Кочубеевского районов Ставропольского края в 2005 году // Архив ИА РАН. Р-1. № 29029, 29030-29031.

7. Панасюк Н.В. Курильницы суворовской катакомбной культуры // Краткие сообщения Института археологии. 2015. № 237. С. 126-141.

8. Панасюк Н.В. Опыт типологического анализа катакомбных курильниц // Проблеми дослідження пам'яток археології Східної України: материалы II-ї Луганської міжнародної історико-археологічної конференції, присвяченої 85-річчю Луганського обласного краєзнавчого музею / отв. ред. В.В. Отрощенко. Луганск: Шлях, 2005. С. 63-65.

9. Панасюк Н.В., Мимоход Р.А. Поздние курильницы восточноманычской катакомбной культуры // Древний Кавказ: ретроспекция культур: тезисы докладов XXIII Крупновских чтений по археологии Северного Кавказа / отв. ред. Л.Т. Яблонский. М.: ИА РАН, 2004. С. 140-142.
10. Панасюк Н.В. Раннекатакомбные курильницы степного Предкавказья // Российская археология. 2010. № 2. C. 25-38.

11. Панасюк Н.В. Курильницы восточноманычской катакомбной культуры как критерий периодизации // Проблемы периодизации и хронологии в археологии эпохи раннего металла Восточной Европы: материалы тематической науч. конф. / отв. ред. Е.А. Черленок. СПб.: Скифия-принт, 2013. С. 44-49.

12. Мимоход Р.А. Лолинская культура. СевероЗападный Прикаспий на рубеже среднего и позднего периодов бронзового века: материалы охранных археологических исследований. Т. 16. М.: ИА РАН, $2013.567 \mathrm{c}$.

13. Державин В.Л. Погребения эпохи бронзы из курганов у хут. Веселая Роща (по материалам экспедиции 1980 г.) // Древности Ставрополья. М.: Наука, 1989. С. $125-194$.

14. Смирнов А.М. Курганы и катакомбы эпохи бронзы на Северском Донце. М.: ИА РАН, 1996. 181 с.

\title{
CATACOMB INCENSE BURNERS OF KURGANS 1 AND 4 OF KOUNAKOVSKY-2 (ON THE EXAMPLE OF ANDROPOVSKIY DISTRICT, STAVROPOL REGION)
}

\section{(C) 2018}

Panasyuk Nathalia Victorovna, candidate of historical sciences, senior lecturer of World History Department People' Friendship University of Russia (Moscow, Russian Federation)

\footnotetext{
Abstract. The author considers the data of Suvorov catacomb culture burials with incense burners, found in kurgans Kounakovsky-2, explored by the expedition of the «Nasledie» in Stavropol Region in 2005. The artefacts from burials of two kurgans (1 and 4) illustrate the typological variety of the catacomb ritual bowls. In addition these kurgans demonstrate good stratigraphy of burials that allows seeing the incense burner's evolution. Such evolution has been already created on data of Vostochnomanych catacomb culture, when early and late types were identified. Suvorov catacomb culture's incense burners of type I, II, VI, X are found in kurgans Kounakovsky-2, one item belongs to the early catacomb period. Stratigraphic data of kurgan 1 indicates almost synchronic construction of the burials, as evidenced by the finds of typologically close incense burners. Kurgan 4 was built at least in four steps, which are illustrated by ritual bowls of early (I, II) and late (VI, X) stages. As a result the authors of the paper justify that Suvorov catacomb culture may be divided in two periods of development, marked by different types of incense burners.

Keywords: archaeological excavations; kurgans; Suvorov catacomb culture; Early catacomb culture; Vostochnomanych catacomb culture; incense burners; typology; stratigraphy; funeral rite's attribute; chronology of archeological culture; Middle Bronze age; Stavropol Region.
}

УДК 902.03

Статья поступила в редакцию 03.05.2018

\section{КУЛЬТУРНАЯ АТРИБУЦИЯ ЖИЛИЩА-МАСТЕРСКОЙ НА ПОСЕЛЕНИИ ТАЛДЫСАЙ НА ОСНОВЕ АНАЛИЗА КЕРАМИКИ}

(C) 2018

Ермолаева Антонина Сергеевна, ведущий научный сотрудник отдела первобытной археологии Калиева Жанаргуль Сериковна, научный сотрудник отдела первобытной археологии Дубягина Екатерина Викторовна, младший научный сотрудник отдела первобытной археологии Институт археологии имени А.Х. Маргулана (г. Алматы, Республика Казахстан)

Аннотаџия. В статье представлена характеристика керамической коллекции из жилища-мастерской поселения металлургов Талдысай, имевшего один период заселения и принадлежавшего к петровской археологической культуре (нуртайский тип памятников для Центрального Казахстана). В предыдущие годы исследований делались попытки на основе керамического материала произвести определение культурной принадлежности теплотехнических сооружений наземного и шахтного типов в жилищно-производственных комплексах, функционировавших в разные хронологические периоды и содержавших разнокультурные материалы. Настоящая публикация является началом работы по систематизации всего массива накопленных керамических материалов поселения, из которых керамика однослойного жилища-мастерской, функционировавшей с начала организации металлопроизводства на поселении, является эталонной и служит репером при проведении классификации всего массива накопленных керамических коллекций. Для анализа из более чем 
100 фрагментов керамики были отобраны наиболее диагностированные от разных сосудов в количестве 41 экземпляра, из которых 35 фрагментов были найдены непосредственно в теплотехнических сооружениях и около них. Уже сейчас можно сделать вывод, что керамический материал явился неопровержимым доказательством принадлежности теплотехнических сооружений наземного и шахтного типов в однослойном жилище-мастерской к кругу памятников петровской археологической культуры нуртайского типа и определил начало появления металлопроизводства на территории Центрального Казахстана первой половиной II тыс. до н.э.

Ключевые слова: Жезказган-Улытауский регион; эпоха бронзы; металлопроизводство; поселение; жилище-мастерская; теплотехнические сооружения; яма-печь шахтного типа; петровская культура; нуртайский тип; фрагменты; керамика; банка; горшечно-баночный сосуд; второе тысячелетие до н.э. острореберный сосуд; двулезвийный пластинчатый нож.

Поселение Талдысай является многокомпонентным памятником, функционировавшим длительное время, в котором отложились материалы петровской и саргаринско-алексеевской археологических культур, андроновской культурной общности и, вероятно, донгальской культуры. Но специальных публикаций, посвященных основным категориям находок поселения, и в том числе керамике, до настоящего времени не было сделано. Не проведено всеобъемлющего исследования керамических коллекций, изучение которых ограничивалось выделением культуроопределяющих групп керамики в результате типологического и технико-технологического анализов. Так как основным занятием жителей поселения, как и всего Жезказган-Улытауского региона в эпоху бронзы, было металлопроизводство, то при исследовании поселения приоритетным являлось изучение материалов, напрямую связанных с медеплавильным и меднолитейным производствами $[1$, с. 135-164; 2 , c. $183-188 ; 3$, с. $126-141 ; 4$, с. 22-38].

Массовый керамический материал служил для определения в общих чертах культурной принадлежности металлургических объектов - печей, тигельных устройств, очагов, а также продукции и отходов металлургического производства. Определенную трудность при исследовании жилищно-производственных комплексов создавали перестройки, неоднократные заселения и сильная смешанность керамического материала. На сохранность памятника негативно повлияли антропогенный и экологический факторы из-за соседства с поселком Талдысай и сезонных разливов реки Бала Жезды. Водой разрушена южная часть у обоих исследованных жилищнопроизводственных комплексов - западного и восточного, в которых отложились материалы андроновской культурной общности и саргаринско-алексеевской культуры. За северной стеной восточного жилищно-производственного комплекса располагалось жилище-мастерская петровско-нуртайского хронологического горизонта, имевшее материалы одного периода заселения [4, с. 22-38]. Культурная принадлежность жилища-мастерской с теплотехническими сооружениями построена на находках медного ножа и керамики с ребром и уступом аналогичных материалам из памятников петровской культуры Северного и Центрального Казахстана. Двулезвийный пластинчатый медный нож с прокованной круглой втулкой, найденный возле металлургической ямы-печи шахтного типа (рис. 1), аналогичен ножам с нуртайского поселения Икпень II [5, с. 76, рис. 26: 6] и петровского поселения Новоникольское I [6, с. 168 , табл. 10А: 14].

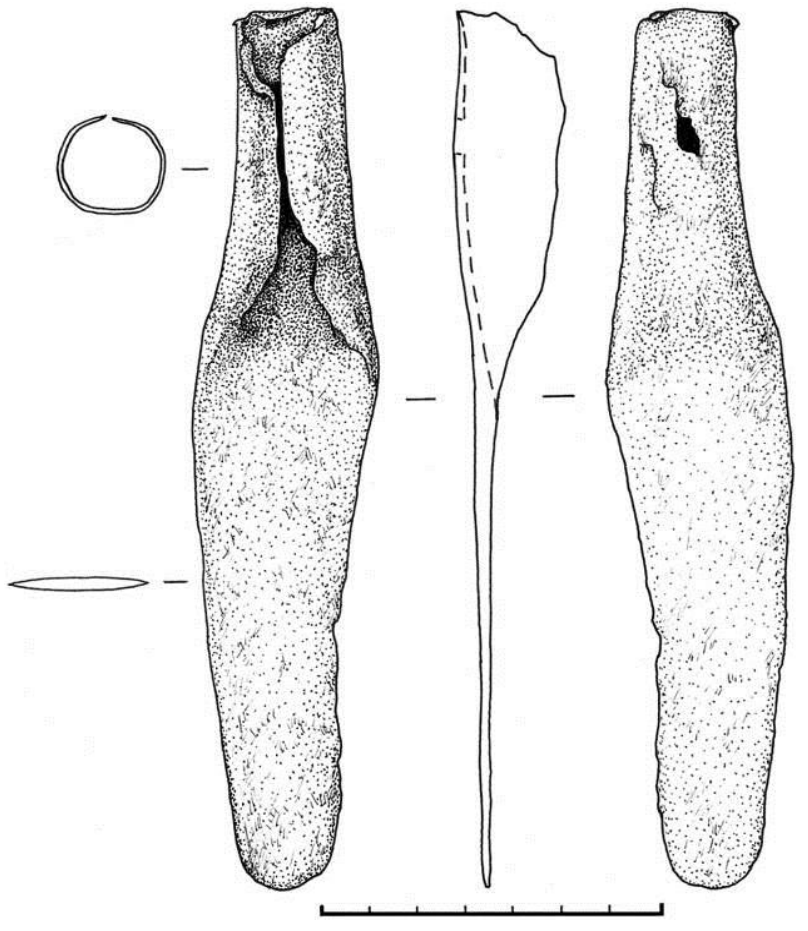

Рисунок 1 - Поселение Талдысай. Раскоп 1, жилище-мастерская. Медь: квадрат 318

Исследование жилища-мастерской не завершено, поэтому в настоящей публикации представлена керамика, найденная в двух раскопанных теплотехнических сооружениях (ТTC) и в слое жилищамастерской около них. Оба ТТС представляли собой ямы-печи шахтного и полушахтного типов, интерпретированные как медеплавильные агрегаты. Ямапечь шахтного типа, видимо, имела дымоход с каменным перекрытием, сохранившийся частично, и канал-воздуховод, отходящий от устья ямы по стене внутрь. Яма-печь полушахтного типа имела каменно-глиняные стенки и хорошо сохранившийся дымоход [3, с. 22-38; 4, с. 126-141]. Для анализа из более чем 100 фрагментов керамики были отобраны наиболее диагностированные от разных сосудов в количестве 41 экземпляра, из которых 35 фрагментов были найдены непосредственно в теплотехнических сооружениях и около них. Фрагменты сосудов представлены венчиками с шейками (рис. 2: 1-5, 7, 9-16; $3: 1,3,4,6,9-11,13 ; 4: 1-3 ; 5: 1,3-5)$, шейками с частью тулова (рис. 2: 6, 8; 3: 2, 7, 12), боковинами (рис. $3: 5,8 ; 5: 2$ ) и донными частями с частью стенок (рис. 4: 4-6; 5: 6). Большую часть из анализируемых фрагментов составили горшечно-баночные формы сосудов - 21 экз., баночные - 12 экз. и со значительной долей вероятности 2 экз. горшечной формы сосуда (по некоторым фрагментам определить форму сосуда удалось предположительно). В большинстве фрагментов зафиксирован плоский срез венчика 
(10 экз.), с уплощенным срезом венчика было на один меньше (9 экз.), из них у 6 экз. уплощение было со скосом наружу, в единичных случаях были венчики с округлой, приостренной и скругленной формы. В большинстве фрагментов шейка была отогнутой (23 экз.) и в том числе у 6 фрагментов она была сильно отогнутой. Почти прямой и невыделенной была шейка у 9 сосудов баночной формы. Особенностью некоторых сосудов являлось наличие «воротничков» или оттянутых венчиков (рис. 2 : 10, 16; 3 : 10), а также утолщенных венчиков (рис. 3: 3). Важной особенностью характеризуемой коллекции керамики является наличие фрагментов от сосудов с уступчатым плечом (рис. 2: 6, 8, 11, 14; 3: 6, 7; 5: 3, 4. 5) и одного фрагмента от острореберного сосуда (рис. 4: 3). Не менее важным является нахождение этого фрагмента от острореберного сосуда под плитами перекрытия медеплавильной печи с дымоходом полушахтного типа. Сосуд имел уплощенный срез венчика, длинную отогнутую шейку, серого цвета обе поверхности, сложный орнамент: под венчиком 2 горизонтальные линии мелкозубчатым штампом, ниже линия из средне зубчатых оттисков, на шейке меандровидные фигуры, выполненные мелкозубчатым штампом, ниже снова горизонтальная линия средне зубчатых оттисков, под которой 2 горизонтальные линии мелкозубчатым штампом (рис. 4: 3). Принадлежность к кругу памятников петровской культуры подтверждают и остальные находки фрагментов керамики из ямы-печи и дымохода, отходящего от нее, а также в слое над ней (рис. 2: 2-6, 12, $14,15,16 ; 3: 2-8,11 ; 4: 1-3)$. В слое около северного конца дымохода найден фрагмент венчика с шейкой от прямостенного баночного сосуда, имевшего приостренный срез венчика, оттянутый наружный край, образовавший воротничок или валиковидный венчик с косыми насечками по нижнему краю (рис. 3: 10). Серия выразительных фрагментов керамики от разных сосудов найдена в слое над ямой-печью шахтного типа и в самой яме-печи (рис. $2: 1,7-9,11,13 ; 3: 1$, $12,13 ; 4: 4-6)$. На одном фрагменте боковины сосуда из дымохода печи выявлена архаичная техника нанесения орнамента в виде наколов отступающей прямоугольной палочки (рис. 3: 8). Орнамент на остальной части керамики выполнен гладким и гребенчатым штампами. Распространенными элементами орнамента были заштрихованные треугольники, зигзаги, елочка, флажки, реже встречаются ямочные вдавления, защипы, налепные шишечки, шагающий штамп, «древо жизни» и т.д.
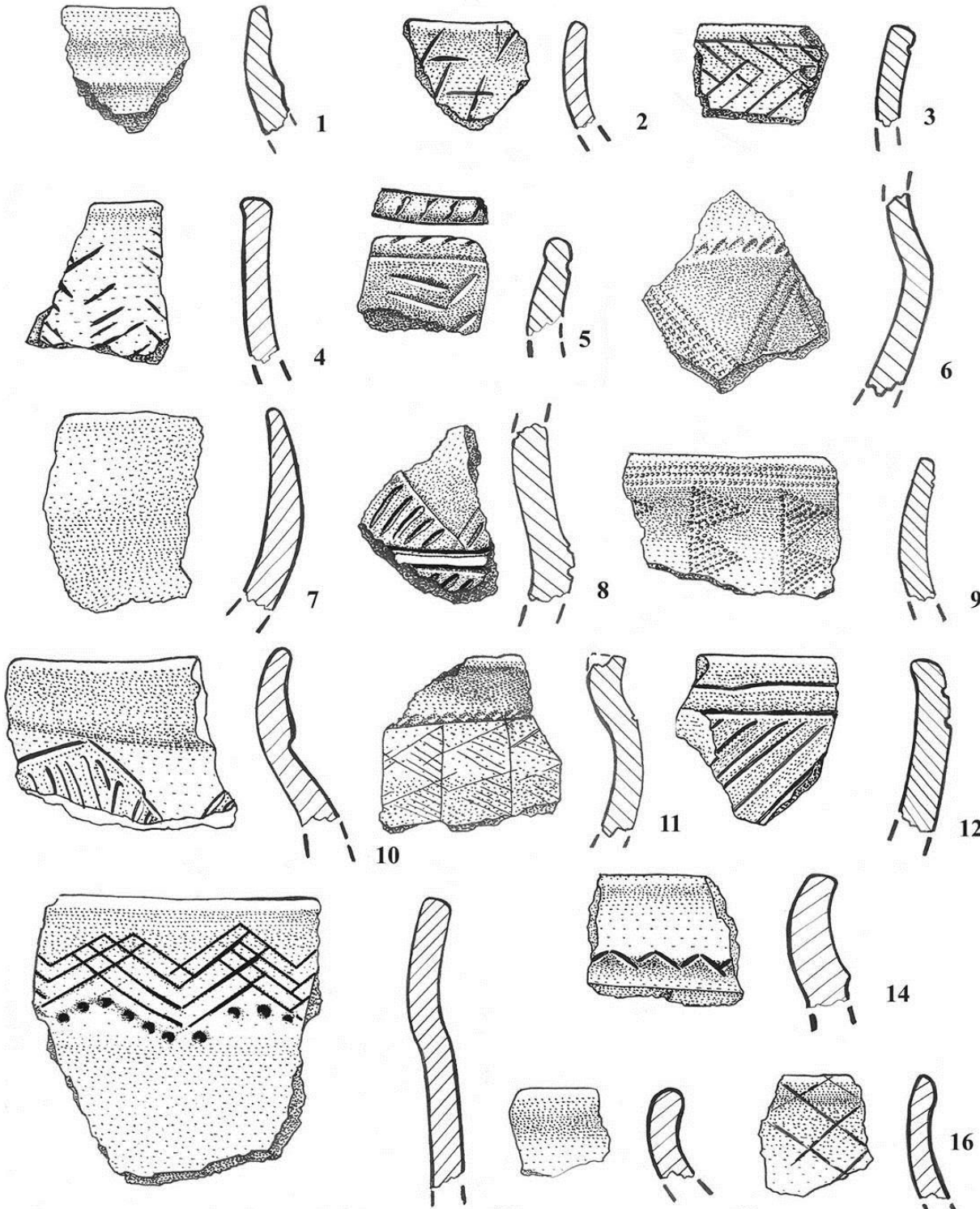

14

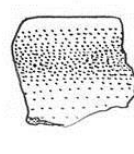

13
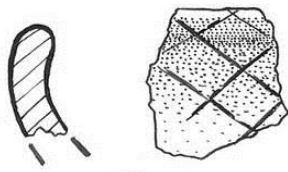

15
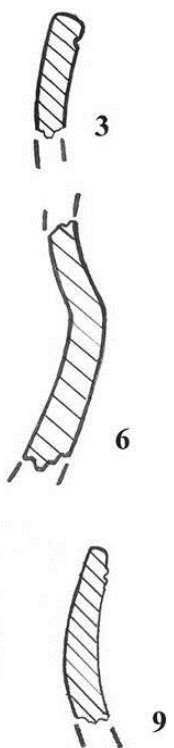

Рисунок 2 - Поселение Талдысай. Раскоп 1, жилище-мастерская. Керамика.

Квадраты: 318 - 1, 7-9, 11, 13; К16 - 3, 4, 12, 14-16; К17 - 5; К18 - 2, 6; М16 - 10 
Ермолаева А.С., Калиева Ж.С., Дубягина Е.В.

Культурная атрибуция жилища-мастерской на поселении Талдысай..

07.00.00 - исторические науки и археология

Так как образцы представлены во фрагментарном виде, возможность определения конструирования начина, конструирование полого тела и придание сосуду формы в большинстве случаев были ограничены. Рассматривались венчики, придонные части и боковины. В основном в качестве исходного сырья для изготовления посуды использовали ожелезненную жирную по пластичности глину, в которой присутствует кварц средней и мелкой фракции. Исходное сырье представлено хорошо очищенной от грубых примесей глиной. Основной искусственной примесью была органика (навоз, органический раствор, выжимка из навоза), затем шамот и дресва (гранитно-гнейсовая), кроме того 3 фрагмента имели включения из руды и шлака.

Зафиксировано 5 рецептов формовочной массы:

1) ИПС + органика + шамот;

2) ИПС + органика + шамот + дресва;

3) ИПС + органика + руда-шлак + шамот + дресва;

4) ИПС + органика + дресва;

5) ИПС + органика.
Традиционно при составлении формовочной массы использовались 2 рецепта: исходное пластичное сырье + органика + шамот и исходное пластичное сырье + органика + шамот + дресва. В качестве органической добавки использовался навоз жвачных животных. Вероятней всего, навоз добавлялся во влажном состоянии, что характеризуется большими поперечными размерами отпечатков, обломков стеблей растений, наличие вытянутых щелевидных пустот от растительных остатков. В большинстве изломов присутствуют обугленные недогоревшие органические остатки. Наличие экскрементов животных независимо от температуры обжига можно определить по образовавшейся раковинистой структуре, а также по следам травянистых стеблей растений [7, с. 31-32]. В данном случае из $100 \%$ добавленной органики в формовочную массу 53\% дали выгоревшие аморфные пустоты, и $38 \%$ керамики были с очень жирным слоем и ржавым налетом, $15 \%$ - с обугленными остатками невыгоревшей органики.
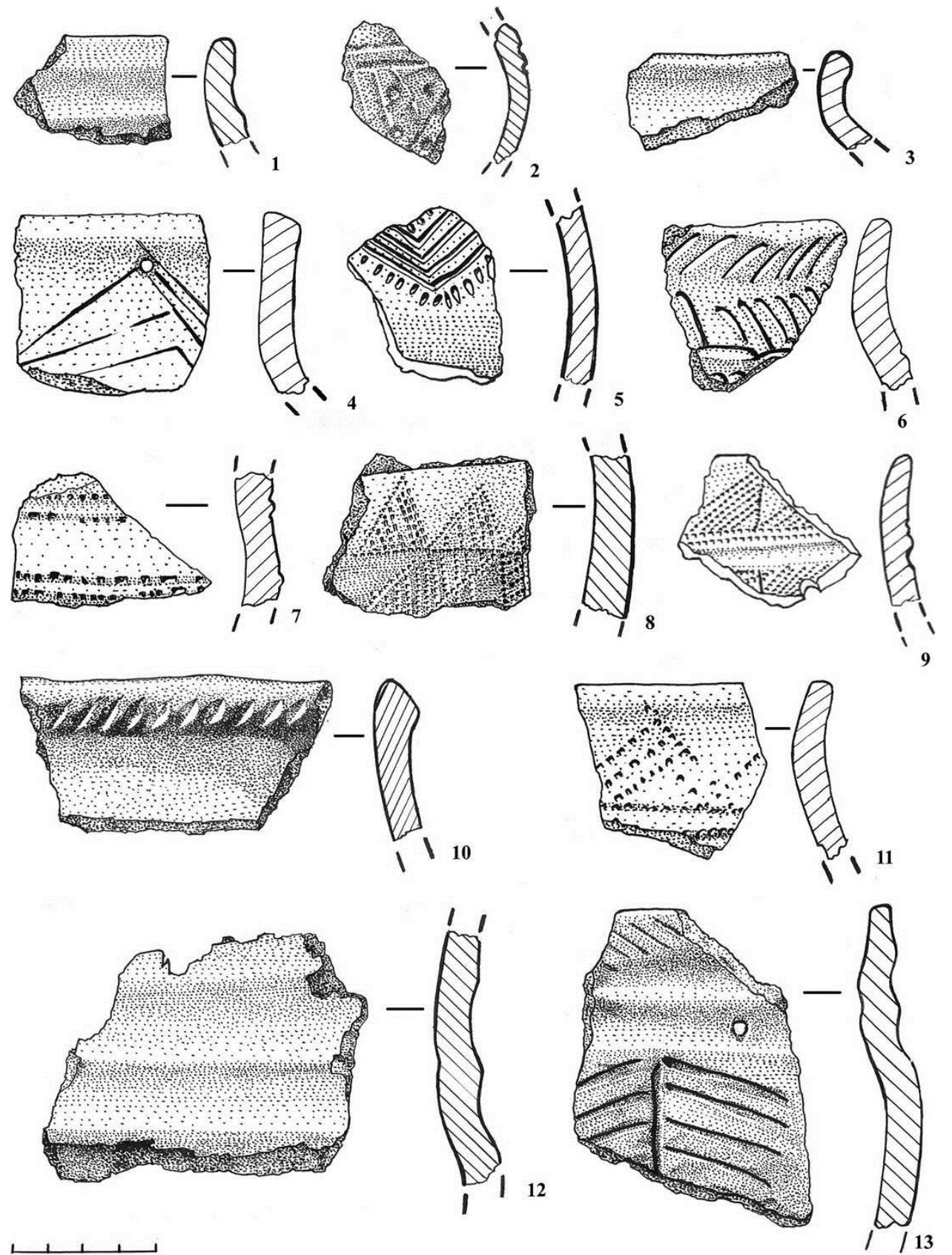

Рисунок 3 - Поселение Талдысай. Раскоп 1, жилище-мастерская. Керамика.

Квадраты: К16, К17, К18 (яма-печь с дымоходом) - 2-8, 10, 11; л8 - 9; 318 (яма-печь шахтного типа) - 13 
Шамот являлся одной из самых распространенных примесей, добавляемой гончарами, при этом во фракции 1,5-2 мм использовался шамот, сходный с основой. Примесь шамота с органикой составила около $61 \%$. Дресва гранитно-гнейсовая - это остроугольные кристаллы кварца, полевого шпата размерами 1,5-2 мм, примесь дресвы составила 28\%. Включения шлака-руды в состав керамики, найденной на территории медеплавильных печей, подтверждает их символическую особенность.

Основные программы конструирования начинов: донно-емкостная и донная. По донным частям можно определить донно-емкостный начин, спирально жгутовой начин, и 1 фрагмент сформован из одного цельного комка глины. Наращивание полого тела происходило с помощью лент и с помощью жгутов.
В спирально-жгутовом начине дно формировалась жгутами по спирали, наращивалось лентами с внешней стороны, плюс дополнительный жгут с внутренней стороны и дополнительный жгут с внешней стороны у 1 фрагмента. Конструирование полого тела, судя по боковым фрагментам, выполнялось ленточным и жгутовым налепами. Примерный диаметр ленты 4,5-5 см, жгута 2-3 см, (диаметр определен примерно из-за размеров фрагментов). Основным приемом формообразования была скульптурная лепка на плоской основе. При обработке поверхности использовалось заглаживание каменным лощилом, мягкой кожей, деревянным либо костяным инструментами. Большинство исследованных фрагментов керамики обожжены, в восстановительной атмосфере, меньше - в окислительной и немного в нейтральной.
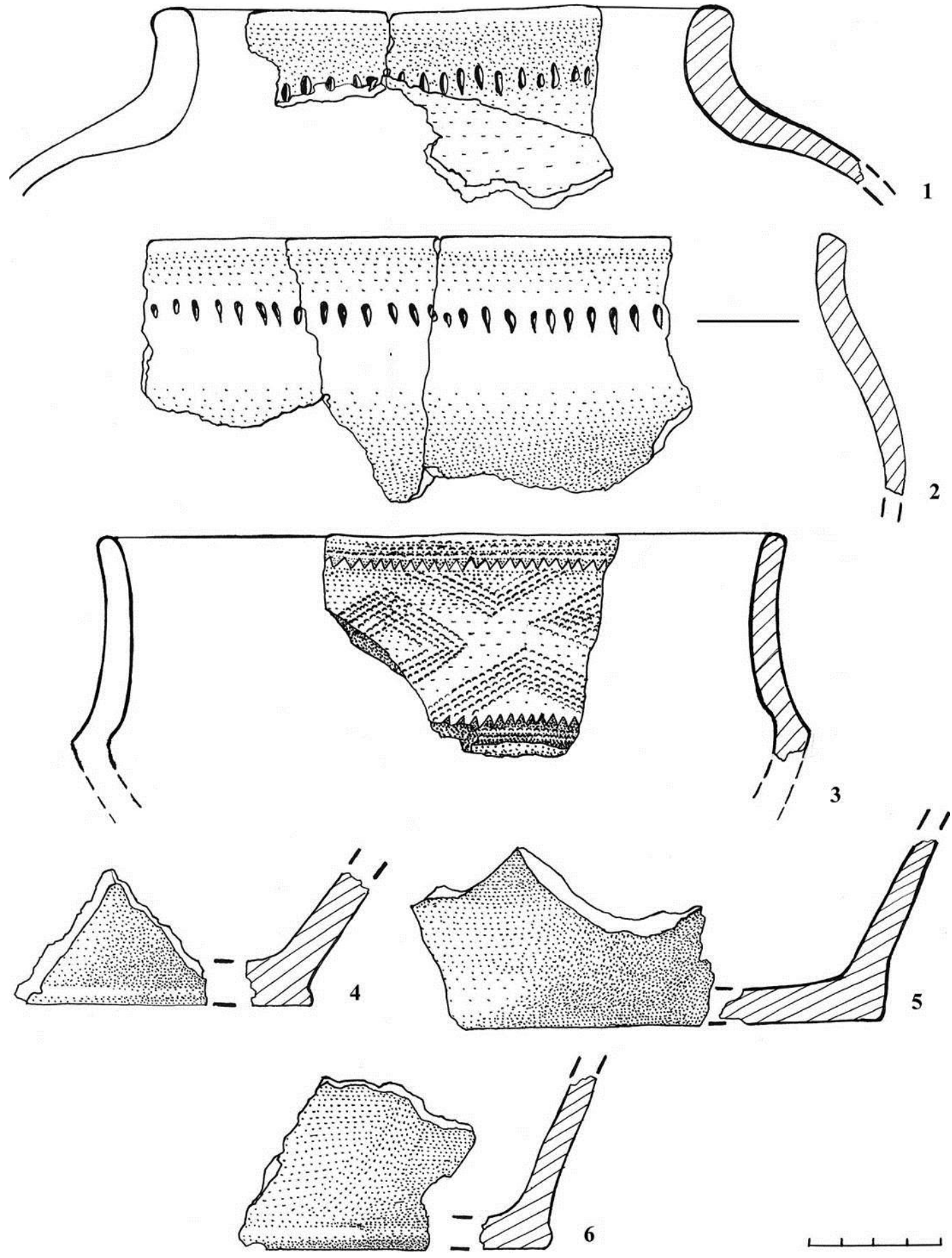

Рисунок 4 - Поселение Талдысай. Раскоп 1, жилище-мастерская. Керамика.

Квадраты К16, К17, К18 (яма-печь с дымоходом) 1-3; 318 (яма-печь шахтная) - 4-6 
По исследованным фрагментам можно сказать, что все сосуды были использованы в быту - это наличие жирного нагара на внешней и внутренней поверхности, следы бытового лощения, жирные прослойки в изломах.

Фрагменты керамики из жилища-мастерской по моделировке верхних частей и орнаменту имеют черты сходства с посудой петровского типа $[8$, c. $48-$ 68 ; с. 58 , рис. $3: 18,26-33 ; 6$, с. 34 , рис. 7 ; с. 49 , рис. 17 ; с. 79 , рис. 3 ; с. 85 , рис. 34$]$, а также с нуртайской $[9$, с. $25-35 ; 10$, с. $22-29 ; 5$, с. 80 , рис. 29 ; с. 82 , рис. 30$]$.

Учитывая ограниченный характер представленной к анализу коллекции керамики из жилища- мастерской, настоящая публикация носит предварительный характер и является началом работы по систематизации всего массива накопленных керамических материалов с поселения. Но уже сейчас можно сделать вывод, что керамический материал явился неопровержимым доказательством принадлежности теплотехнических сооружений наземного и шахтного типов на поселении Талдысай к кругу памятников петровской культуры нуртайского типа и существования металлопроизводства на территории Центрального Казахстана в первой половине 2 тыс. до н.э.

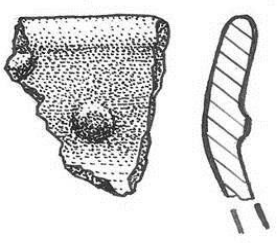

1

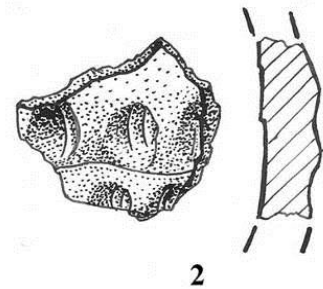

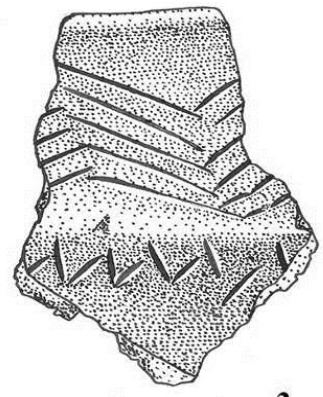
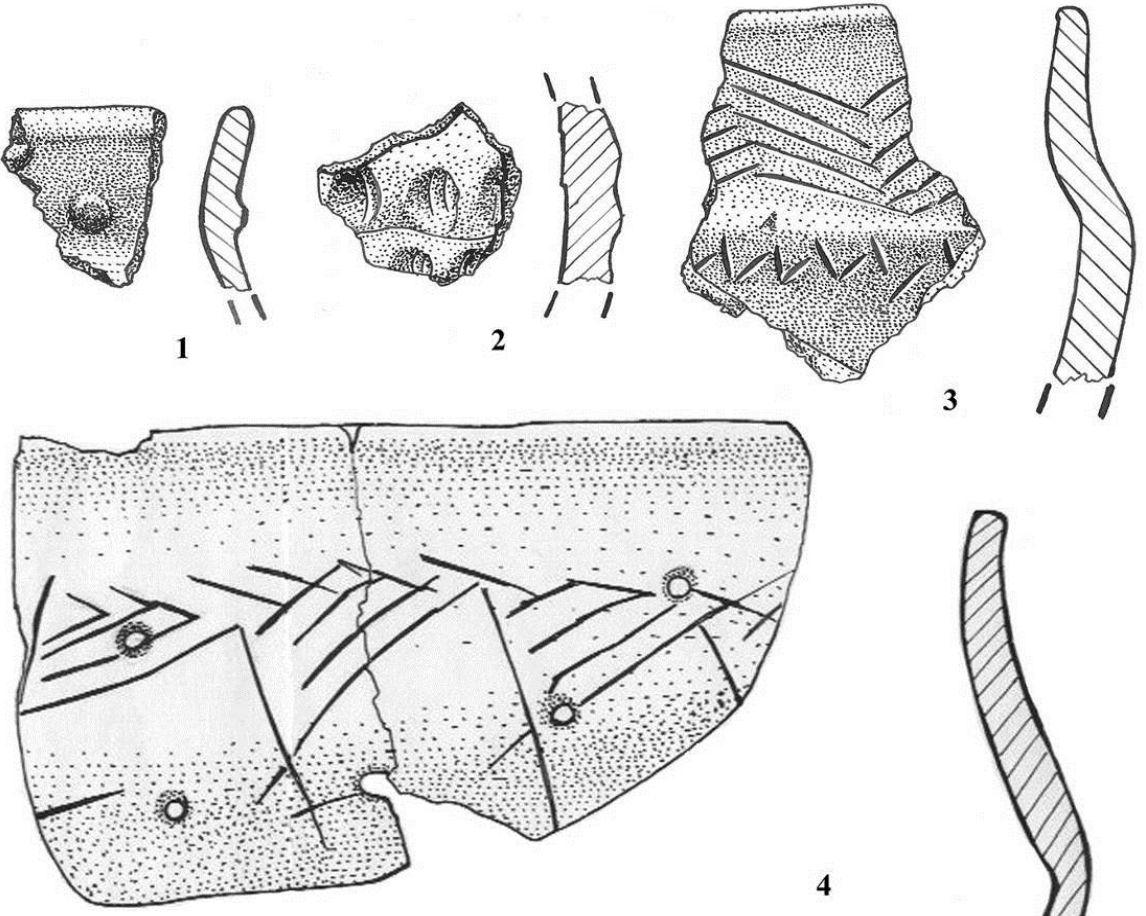

4
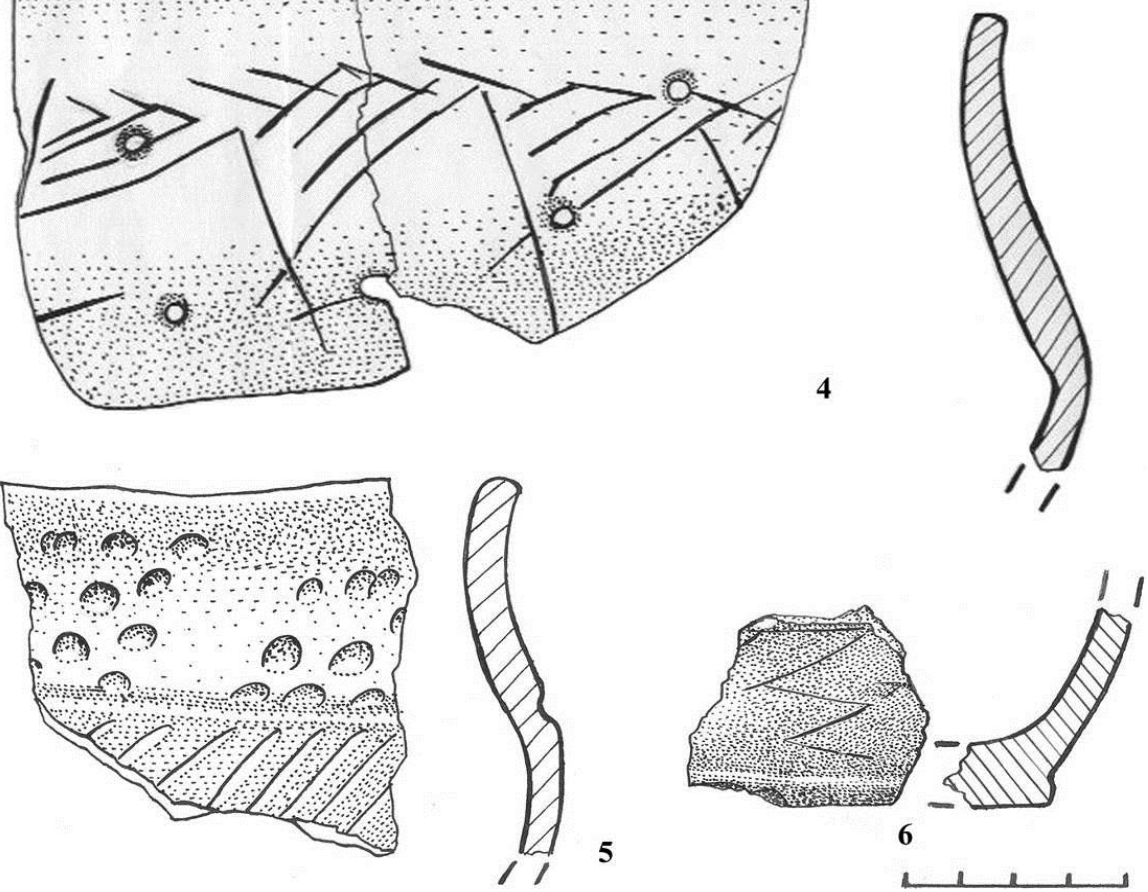

Рисунок 5 - Поселение Талдысай. Раскоп 1, жилище-мастерская. Керамика. Квадраты; К14-Л14 (стена) - 4; К15 - 6; М17 - 1, 2, 5; Н17 - 3

\section{Список литературы:}

1. Ермолаева А.С., Ержанова А.Е. Характеристика раскопанных объектов нижнего слоя поселения Талдысай // Комплекс памятников в урочище Талдасай. Т. 1 / О.А. Артюхова, Ж. Курманкулов, А.С. Ермолаева, А.Е. Ержанова. Алматы, 2013. С. 135-167.

2. Ермолаева А.С., Дубягина Е.В., Калиева Ж.С. Сопла как показатель использования наземных теплотехнических сооружений на поселении Талдысай // Вестник КазНПУ им. Абая. Серия «Исторические и социально-политические науки». 2017. № 3 (54). C. $183-188$.

3. Ермолаева А.С., Ержанова А.Е., Дубягина Е.В. Теплотехнические сооружения наземного типа на поселении Талдысай // Научно-технический прогpecc: актуальные и перспективные направления будущего: сборник материалов VI междунар. науч.практ. конф. (18 августа 2017 года). Т. І. Кемерово: ЗапСибНЦ, 2017. С. 22-38.

4. Ермолаева А.С. Пертовско-нутртайские жилища-мастерские на поселении Талдысай // Актуальные проблемы археологии Евразии: междунар. науч.практ. конф., 18-19 октября 2016 г., Алматы, 2016. C. $126-141$.

5. Ткачев А.А. Центральный Казахстан в эпоху бронзы. Ч. 1. Тюмень, 2002. 289 с.

6. Зданович Г.Б. Бронзовый век Урало-Казахстанских степей. Свердловск: Урал. ун-т, 1988. 177 с. 
7. Бобринский А.А. Гончарная технология как Центрального и Северного Казахстана. Караганда: объект историко-культурного изучения // Актуальные проблемы изучения древнего гончарства (коллективная монография). Самара, 1999. С. 31-32.

8. Зданович Г.Б. Основные характеристики петровских комплексов Урало-Казахстанских степей (к вопросу о выделении петровской культуры) // Бронзовый век степной полосы Урало-Иртышского междуречья. Челябинск: Башк. ун-т, 1983. С. 48-68.

9. Ткачев А.А. Периодизация и хронология алакульских памятников Центрального Казахстана // Вопросы периодизации археологических памятников

Kap. ун-т, 1987. С. 25-35.

10. Ткачев А.А. Особенности нуртайских комплексов Центрального Казахстана // Вестник археологии, антропологии и этнографии. Вып. 2. Тюмень, 1999. C. $22-29$.

Статья публикуется при поддержке гранта: ИРН АР05132375 «Исследование многокомпонентной системы жизнеобеспечения древних коллективов по материалам поселений Центрального Казахстана».

\title{
CULTURAL ATTRIBUTION OF THE DWELLING-WORKSHOP ON THE BASIS OF THE TALDYSAY SETTLEMENT CERAMICS ANALYSIS
}

(C) 2018

\author{
Yermolayeva Antonina Sergeevna, leading researcher of Prehistoric Archeology Department \\ Kaliyeva Zhanargul Serikovna, researcher of Prehistoric Archeology Department \\ Dubyagina Ekaterina Viktorovna, junior researcher of Prehistoric Archeology Department \\ A.Kh. Margulan Institute of Archaeology (Almaty, Republic of Kazakhstan)
}

\begin{abstract}
The following paper considers important characteristics of classical ceramic collection from the dwelling-workshop situated in the metallurgical settlement Taldysay. The workshop had one period of settlement and belongs to the Petrov archeological culture (the type of the monument is Nurtai for Central Kazakhstan). In previous years of the research, we made attempts to determine the cultural affiliation of the thermal engineering structures on the basis of ceramic material that constitutes ground and mine types in dwelling and production complexes that functioned in different chronological periods and contained various cultural materials. Due to the fact that the collection is quite limited, the present publication consists of the preliminary analysis of the artifacts and includes systematization of the accumulated ceramic materials from the settlement. From 100 fragments, only 41 specimens were selected for the further analysis, and 35 of which were found directly in the heat engineering facilities and near them. Importantly, even now we can conclude that the ceramic material proves that the thermal engineering structures of ground and mines types in a single-layer dwelling-workshop belong to the monuments of Petrov archeological culture of Nurtai type. Finally, the considered collection determines the start of the metal production on the territory of Central Kazakhstan by the first half of the second millennium BC.

Keywords: Zhezkazgan-Ulytay Region; bronze age; metal production; settlement; dwelling-workshop; heat engineering facilities; mine type pit-furnace; fragments; ceramics; potted jar; sharp-edged vessel; double-blade plate knife; second millennium BC; Petrov's culture; Nurtai type.
\end{abstract}

УДК 902/904, 902.6

Статья поступила в редакцию 07.06.2018

\section{НОВЫЕ ПОДХОДЫ К МОДЕЛЯМ ГЕНДЕРНЫХ РОЛЕЙ ПОЗДНЕГО БРОНЗОВОГО ВЕКА ЮЖНОГО ПРИУРАЛЬЯ: КАЗБУРУНОВСКИЙ АРХЕОЛОГИЧЕСКИЙ МИКРОРАЙОН ПО РЕЗУЛЬТАТАМ БИОАРХЕОЛОГИЧЕСКОГО АНАЛИЗА}

(C) 2018

Щербаков Николай Борисович, кандидат исторических наук, научный сотрудник лаборатории методологии и методов гуманитарных исследований

Шутелева Ия Александровна, кандидат исторических наук, научный сотрудник лаборатории методологии и методов гуманитарных исследований

Леонова Татьяна Алексеевна, кандидат исторических наук,

заведующий лабораторией методологии и методов гуманитарных исследований

Башкирский государственный педагогический университет им. М. Акмулль (г. Уфа, Российская Федераџия)

Горшков Константин Александрович, криминалист-эксперт медико-криминалистического отделения Бюро судебно-медицинской экспертизы (2. Уфа, Российская Федерация)

Гольева Александра Амуриевна, доктор географических наук, ведущий научный сотрудник отдела географии и эволюции почв

Институт географии РАН (г. Москва, Российская Федераичия)

Батурина Александра Николаевна, студент института истории и государственного управления Башкирский государственный университет (г. Уфа, Российская Федерация)

Аннотаџия. Комплексные археологические исследования, проведенные на памятниках развитого, классического позднего бронзового века на территории Южного Приуралья, Казбуруновского археологического микрорайона, позволили применить метод остеобиографии к реконструкции гендерных особенностей погребального обряда. Полученные радиоуглеродные даты позволили не только удревнить историю проживания 